\title{
Radon Concentrations in Canned Liquid Juice
}

\author{
A. A. Abojassim \\ University of Kufa, Faculty of Science, Physics Department, Kufa, Najaf Governarate, Iraq
}

\section{ARTICLE INFO}

Article history:

Received 6 February 2020

Received in revised form 1 April 2020

Accepted 6 April 2020

Keywords:

Ionization radiation

Alpha particles

${ }^{222} \mathrm{Rn}$ concentrations

Canned liquid juice

\begin{abstract}
A B S T R A C T
This study was performed at University of Kufa, Iraq, using canned liquid juice samples found in Iraqi markets due to the absence of environmental contamination from radionuclides emitting ${ }^{222} \mathrm{Rn}$ concentrations using $\mathrm{RAD}-7$ detectors. The annual effective dose (AED) of ${ }^{222} \mathrm{Rn}$ was estimated for children and adults from the ingestion of canned liquid juice samples. The estimated concentrations of ${ }^{222} \mathrm{Rn}$ in unit $(\mathrm{mBq} / \mathrm{L})$ ranged from 35.4 to 249.1 , with an average of $77.880 .24 \pm 15.42$. It also shows that the AED values for children and adults in $(\mathrm{nSv} / \mathrm{y})$ ranged from 19.11 to 134.48 with an average of $43.31 \pm 8.32$ and from 22.67 to 159.55 with an average of $51.39 \pm 9.88$, respectively. All estimated results of ${ }^{222} \mathrm{Rn}$ concentrations for juice samples were lower than the natural limits provided by the WHO and the European Union Commission to the public ( 0.5 and $1 \mathrm{~Bq} / \mathrm{L}$, respectively). Therefore, there are no health hazards from drinking juice sold in Iraq markets.
\end{abstract}

(C) 2021 Atom Indonesia. All rights reserved

\section{INTRODUCTION}

Significant damage can be done at the cellular level because of the ionizing radiation exposure. However, given that alpha and beta radiation are generally categorized as non-penetrating radiation, only localized damage may result from direct exposure to these forms of radiation. One example is radiation burns to the skin [1,2]. Humans on earth are constantly subjected to radiation this way. There are two types of radiation sources that can be classified as follows: natural and man-made radiation [3]. Gamma rays and neutrons are more intense compared to alpha and beta particles, while being able to do specific harm to the body [4].

Inert gas has the potential to migrate through solids and mix with air, then accumulating in enclosed spaces or areas where airflow is limited to which large concentrations of radon gas can reach the human respiratory tract when breathing $[5,6]$. Radon $\left({ }^{222} \mathrm{Rn}\right)$ hazard to human health lies in the nature of Kamal ambient air. It is a heavy elements that can possibly harm the respiratory tract when it reaches the lung wall, potentially causing lung cancer $[7,8]$. The radiological influence of soil fertilizer uses is attributable to the internal

Corresponding author.

E-mail address: ali.alhameedawi@uokufa.edu.iq

DOI: https://doi.org/10.17146/aij.2020.1030 irradiation of the respiratory organ by alpha particles, short-lived radon-thoron progeny, and the body's external irradiation through radionuclideemitting gamma rays. ${ }^{222} \mathrm{Rn}$ is carcinogenic to human and responsible for natural radiation exposure to human $[9,10]$. It exists on air, water, and soil, with the main source came from soil. While radon gas has always been present in the atmosphere, its contribution to radiation exposure to human has risen in recent years [11]. Radon emanates from uranium, a naturally occurring mineral that exists in rocks and soil. Radon is the second leading cause of lung cancer mortality in the United States [12]. Several researches investigated the calculation of the radon concentration levels in liquid samples [13-17]. The goal of this work is to analyze the content of ${ }^{222} \mathrm{Rn}$ radionuclide in several liquid canned juices (made in different countries) commonly consumed in Iraq using alpha spectroscopy (RAD-7).

\section{EXPERIMENTAL METHODS}

Concentration of radon gas is analyzed in fifteen canned juice samples most commonly sold in Iraq. The samples are listed in Table 1. Most of canned food and liquid samples are not produced locally in Iraq. Samples were packed at a constant volume of 0.25 liters, so they can be used 
with RAD-7 detector (DURRIDGE Company, Inc.-Bedford, MA, U.S.A.) (see Fig. 1). The experimental method meets the standard adopted for Radon-in-water measurement [14-17].

Table 1. Information about canned liquid juice samples

\begin{tabular}{cccc}
\hline No. & Sample code & Sample Name & Origin \\
\hline 1 & J1 & Blue Dana & Kuwait \\
2 & J2 & Jeehan & Jordan \\
3 & J3 & Ogarit & Syria \\
4 & J4 & Raubi & Lebanon \\
5 & J5 & Mizo & Saudi Arabia \\
6 & J6 & Rayaheen & Iraq \\
7 & J7 & Original & Saudi Arabia \\
8 & J8 & Rauch & Austria \\
9 & J9 & Sunfor & Kuwait \\
10 & J10 & Kazouza & Lebanon \\
11 & J11 & Balkan & Bulgaria \\
12 & J12 & Lafi & Jordan \\
13 & J13 & Sirma & Turkey \\
14 & J14 & Rani & Saudi Arabia \\
15 & J15 & Serene & Jordan \\
\hline
\end{tabular}

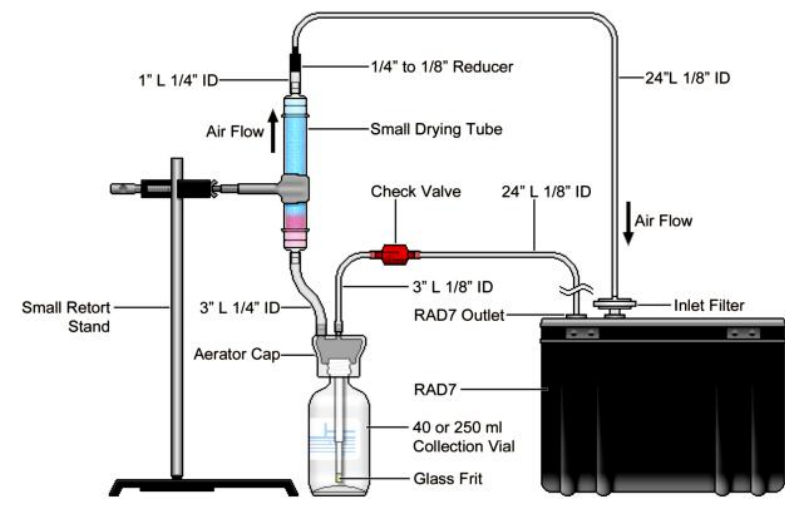

Fig. 1. RAD-7 experimental set-up [18-20]

RAD-7 detector consists of semiconductor materials. Essentially, it consists of a cell filled in regularly. This cell is filled with air by means of a small pump that draws air into the cell at each preselected interval at which the radon or ${ }^{218} \mathrm{Po}$ may decay so that it can be counted while the process is repeated. Technically, the RAD-7 system is based on a solid state detector in its operation. The silicon ion detector converts the radiation into electric signal through the semiconductor material. One of the advantages of solid-state detectors is that they can discern the intensity of the incoming alpha radiation electronically. Many radionuclides, such as ${ }^{218} \mathrm{Po}$, can be detected with an energy of $6.00 \mathrm{MeV}$ or ${ }^{214} \mathrm{Po}$ of $7.69 \mathrm{MeV}$ [18].

The AED based on the ingestion of juice was calculated according ICRP. The annual effective dose $\left(E_{d}\right)$ can be determined by Eq. (1) [21]:

$$
E_{d}=A_{c} A_{i} C_{f}
$$

where $\mathrm{A}_{c}$ is ${ }^{222} \mathrm{Rn}$ concentration in juice samples $(\mathrm{Bq} / \mathrm{L}), \mathrm{A}_{\mathrm{i}}$ is annual intake in unit $(\mathrm{L} / \mathrm{y})$ and $\mathrm{C}_{\mathrm{f}}$ is the conversion factor in unit $(\mathrm{Sv} / \mathrm{Bq})$. The conversion factor is 5.9 and $3.5 \mathrm{nSv} / \mathrm{Bq}$ for children and adults, respectively, in accordance to UNSCEAR2000 report [22].

\section{RESULTS AND DISCUSSION}

Results were obtained from fifteen canned liquid juice samples collected from the market of Al-Najaf, as shown in Table 2. In sample j7 (originally made in Saudi Arabia) the highest concentration of ${ }^{222} \mathrm{Rn}$ was found, accounted for $249.1 \mathrm{mBq} / \mathrm{L}$. The lowest ${ }^{222} \mathrm{Rn}$ concentration are found in samples $\mathrm{j} 10$ and $\mathrm{j} 11$, with concentration of $35.4 \mathrm{mBq} / \mathrm{L}$ (Kazouza made in Lebanon and Balkan made in Bulgaria). For all samples analyzed, the mean value was $80.24 \mathrm{mBq} / \mathrm{L}$ with standard error of $15.42 \mathrm{mBq} / \mathrm{L}$. The difference in the ${ }^{222} \mathrm{Rn}$ concentration results for canned liquid juice samples may be due to the original composition of materials and water for the ingredients of the test samples. The average value of ${ }^{222} \mathrm{Rn}$ is higher in Saudi Arabia than in any other country. It can be noted from Table 2 along with Fig. 2. Compared with WHO standard and EU Commission of Drinking Water, the ${ }^{222} \mathrm{Rn}$ concentrations of liquid canned juice in the current study were found to be lower than WHO limit at $0.5 \mathrm{bq} / \mathrm{L}$ [23] and the EUC limit $1 \mathrm{bq} / \mathrm{L}$ [24].

Table 2. Results of ${ }^{222} \mathrm{Rn}$ concentrations canned liquid juice samples

\begin{tabular}{ccc}
\hline No. & Sample code & ${ }^{222}$ Rn concentrations $(\mathbf{m B q} / \mathbf{L})$ \\
\hline 1 & J1 & 124.8 \\
2 & J2 & 106.5 \\
3 & J3 & 71.2 \\
4 & J4 & 178.2 \\
5 & J5 & 71 \\
6 & J6 & 71.2 \\
7 & J7 & 249.1 \\
8 & J8 & 35.5 \\
9 & J9 & 35.6 \\
10 & J10 & 35.4 \\
11 & J11 & 35.4 \\
12 & J12 & 47.46 \\
13 & J13 & 35.6 \\
14 & J14 & 53.4 \\
15 & J15 & 53.3 \\
& Average \pm S.E & $80.24 \pm 15.42$ \\
\hline
\end{tabular}

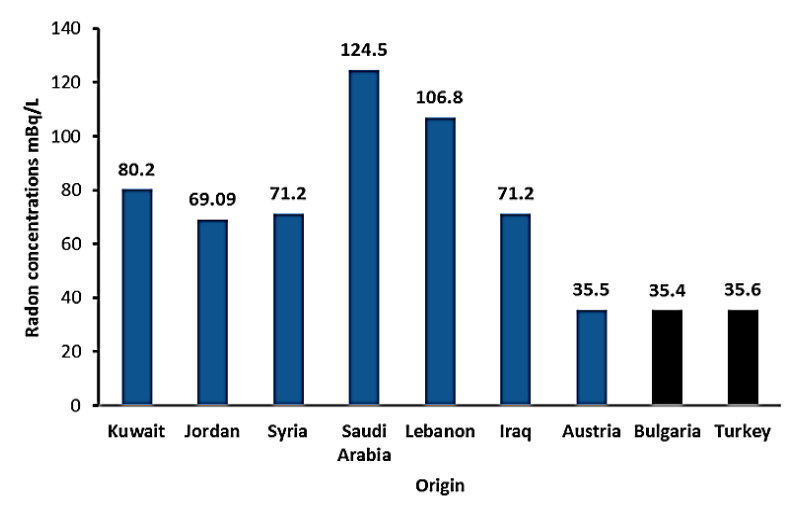

Fig. 2. Comparison the average value of ${ }^{222} \mathrm{Rn}$ concentrations in different counties of present study 
Table 3 reveals AED when children and adults consume the canned liquid juice. Table 3 indicates that AED in children ranges between $19.11 \mathrm{nSv} / \mathrm{y}$ and $134.48 \mathrm{nSv} / \mathrm{y}$, averaging for $43.31 \pm 8.32 \mathrm{nSv} / \mathrm{y}$. Meanwhile, AED in adults ranges between $22.67 \mathrm{nSv} / \mathrm{y}$ and $159.55 \mathrm{nSv} / \mathrm{y}$, with an average of $51.39 \pm 9.88 \mathrm{nSv} / \mathrm{y}$.

Table 3. AED in children and adult

\begin{tabular}{ccc}
\hline \multirow{2}{*}{ Sample code } & \multicolumn{2}{c}{ AED $(\mathbf{n S v} / \mathbf{y})$} \\
& Children & Adults \\
\hline J1 & 67.37 & 79.93 \\
J2 & 57.49 & 68.21 \\
J3 & 38.44 & 45.60 \\
J4 & 96.20 & 114.14 \\
J5 & 38.33 & 45.48 \\
J6 & 38.44 & 45.60 \\
J7 & 134.48 & 159.55 \\
J8 & 19.16 & 22.74 \\
J9 & 19.22 & 22.80 \\
J10 & 19.11 & 22.67 \\
J11 & 19.11 & 22.67 \\
J12 & 25.62 & 30.40 \\
J13 & 19.22 & 22.80 \\
J14 & 28.83 & 34.20 \\
J15 & 28.77 & 34.14 \\
Average \pm S.E & $43.31 \pm 8.32$ & $51.39 \pm 9.88$ \\
\hline
\end{tabular}

Table 3 and Fig. 3 indicate that the AED in adult samples are higher than that in the children samples. The high intake rate is responsible for this greater dose. The obtained data show that in all samples of vegetable and fruit juices, the AED is lower than the $1 \mathrm{mSv} /$ year allowable limit recommended by the ICRP [25]. It is therefore possible to assume that ${ }^{222} \mathrm{Rn}$ concentration in samples of canned juices were small, and there were no health risks when consumed in Iraq or elsewhere by various age groups.

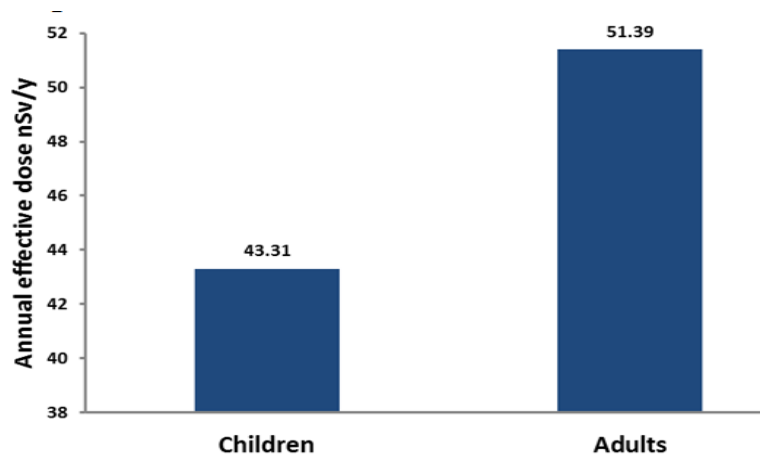

Fig. 3. Compare the average of AED in children and Adults age group.

\section{CONCLUSION}

The concentatuons of ${ }^{222} \mathrm{Rn}$ in canned liquid juices were measured using RAD-7 detection technique. The measured concentations of ${ }^{222} \mathrm{Rn}$ were found to be lower than the recommended WHO and EUC values at $0.5 \mathrm{~Bq} / \mathrm{L}$ and $1 \mathrm{~Bq} / \mathrm{L}$ respectively. The values of AED in all samples are less than the allowed maximum level of $1 \mathrm{mSv} / \mathrm{y}$. it can be concluded that drinking from the liquid canned juices studied pose no health risks to the consumer.

\section{ACKNOWLEDGMENT}

The author acknowledge the support from the Departmemt of Physics, University of Kufa and for all the peoples who contribute by advise or help to make this research work happen.

\section{REFERENCES}

1. J. Boice and D. John, Int. J. Radiat. Biol. 93 (2017) 1079.

2. V.H.P. Ramos, G.G.F. Rojas, C.A. Lorenzo et al., React. Funct. Polym. 126 (2018) 74.

3. A.A. Abojassim, M.A. Hassan, L.A. Najam et al., Environ. Earth. Sci. 78 (2019)132.

4. Anonymous, Sources, Fields, Measurements, and Applications, $2^{\text {nd }}$ ed., Radiation Dosimetry Vol. III, F.H. Attix and E. Tochilin (Eds.), Academic Press, New Yok (2016) 964.

5. O. Ilic, B. Peter, G. Chen et al., Nat. Nanotechnol. 11 (2016) 320.

6. A.A. Abojassim, Iran J. Med. Phys. 16 (2019) 120.

7. M.A. Zbalh, A.A. Hussien, A.A. Abojassim et al., Indian J. Public. Health. Res. Dev. 10 (2019) 1956.

8. M.S. Aswood, A.A. Abojassim and S.A. Mustafa, Radiat. Detect. Technol. Methods 3 (2019) 57.

9. D.A. Salim and A.E. Sameera, Energy Procedia 157 (2019) 918.

10. A.A. Abojassim and H.R. Leith, Nat. Env. \& Poll. Tech. 18 (2019).

11. A.A. Abojassim, H.H. Al-Gazaly, E.S. Obide et al., Int. J. Environ. Anal. Chem. 100 (2020) 99.

12. A.A. Abojassim and D.J. Lawi, Plant Arch. 18 (2018) 1137.

13. W.H. Clements and C. Kotalik, Freshw. Sci. 35 (2016) 126. 
14. A.M. El-Taher, A.A. Abojassim, L.A. Najam et al., Iran J. Med. Phys. 17 (2020) 15.

15. A.A. Abojassim, S.H. Kadhim, H.A. Mraity et al., Wa. Sci. Technol.: Water Supply 17 (2017) 206.

16. A.A. Abojassim, S.K. Alzurfi and H.A. Mraity, Pakistan J. Sci. Ind. R. Series A: Phys. Sci. 61 (2018) 43.

17. A.A. Abojassim, Iran J. Med. Phys. 16 (2019) 1.

18. L.C. Wie, J.W. Bae, H.R. Kim et al., Radiat. Meas. 121 (2019) 54.

19. A.S. Alaboodi, N.A. Kadhim, A.A. Abojassim et al., Int. J. Radiat. Res. 18 (2020) 1.

20. G.M. Shilpa, B.N. Anandaram and T.L. Mohankumari, J. Radiat. Res. Appl. Scie. 10
(2017) 262.

21. M.N. Alam, I. Chowdhury, M. Kamal et al., Radiat. Prot. Dosim. 82 (1999) 207.

22. A. Binesh, S. Mohammadi, A.A. Mowlavi et al., Afr. J. Water Conserv. Sustain. 5 (2017) 201.

23. V. Duggal, S. Samriti and R. Mehra, Appl. Radiat. Isot. 123 (2017) 36.

24. Anonymous, Commission of the European Communities, Directorate-General for Regional Policy, European Commission, Office for Official Publications of the European Communities (2001).

25. C. Directive, Off. J. Eur. Comm. 330 (1998) 32. 